\section{How hospital geriatric care is changing during COVID-19 pandemic: drawbacks and possible solutions}

\author{
Liliana Mazza, Daniela Pinto, \\ Pietro Calogero \\ Acute Geriatric Unit, COVID+, \\ Policlinico Sant'Orsola-Malpighi, \\ Bologna, Italy
}

\begin{abstract}
Since the outbreak of coronavirus disease-19 (COVID-19) pandemic, geriatric population has been the most affected due to the peculiarities of the disease in terms of contagiousness and severity. Major changes have been implemented in healthcare structures and facilities worldwide in order to accomplish the necessity to host and isolate infected patients. Simultaneously, many critical issues have emerged concerning medical and nursing assistance to elderly patients, due to the new arrangement of wards and innovative work tools. Acute Geriatric Units dedicated to COVID-19 have been asked to put giant efforts in adapting to new care models in mobility, communication, feeding, basic assistance and caregivers' involvement.

The purpose of this dissertation is to highlight the role of Geriatricians as proactive contributors of new approaches to elderly patients in times of COVID-19, in order to develop a further-thinking working methodology.
\end{abstract}

\section{Introduction}

Coronavirus disease-19 (COVID-19) has spread rapidly from China throughout the whole world since late January 2020. By April $16^{\text {th }}, 165,155$ cases have been registered in Italy, which is at the second place in Europe for number of infected, while currently maintaining the primacy over the number of deaths, $21,647 .{ }^{1}$ These numeric evidences may be underestimated as a consequence of methodological concerns in data collection, which are still under debate. Two relevant issues are a large presence of asymptomatic subjects and swab testing strategies. $^{2}$

Among dead people, those aged 70 years or more accounted for around $83.5 \%$. Lethality rate is higher in people aged $80-89$ (30.5\%); almost a quarter of infected aged either 70-79 and $>90$, respectively, have died. ${ }^{3}$ Median age of dead is 80 years old; this number largely differs from median age of infected, attested at $62 .{ }^{4}$

While severe acute respiratory syndrome-coronavirus-2 (SARS-CoV-2)-related disease, for its intrinsic clinical features, ${ }^{5,6}$ has all the credentials to be itself a serious issue, frailty and multimorbidity is supposed to play a consistent role in increasing mortality rates in elderly people. COVID-19 infection may be a dramatic stressor for frail patients to sustain, ${ }^{7}$ therefore unleashing a cascade of organ failure, progressive and potentially fatal. The coexistence of multiple chronic pathological conditions, characteristic although heterogeneous in the elderly, ${ }^{8}$ represent a critical substrate of fertile ground for the virus to diffuse and operate.

Anyhow, geriatricians are used to complexity and vulnerability. In Geriatric research, intense efforts have been put in the last years in providing prognostic measurements adaptable to frail older adults' management ${ }^{9}$ and in detecting needs and uses of healthcare system facilities. ${ }^{10}$ Among clinicians, geriatricians may be considered flexible as they are keen to personalize cure and assistance to each unique subject, tailoring clinical approach to the patient.

The main purpose of this dissertation is to point out some reflections on how geriatric care has changed during the outbreak of COVID-19. Practically, some major geriatric care issues are briefly discussed below and linked to the current literature. Some possible solutions to the mentioned critical points are proposed

\section{Drawbacks in geriatric care}

\section{General context}

Hospitals worldwide are hosting COVID-19 patients in specific areas, created to isolate infected people with specific medical needs. Due to the variability of severity patterns of the disease, hospital settings are differentiated in terms of intensity of care. Personal protective equipment (PPE) are supplied to healthcare workers to prevent and reduce the risk of transmission of the pathogen. PPE may slightly differ from a ward to another, mostly due to shortage of devices, ${ }^{11}$ whereas basic equipment consists of: face masks, eye protection, cuff, gowns, gloves.

\section{Intensity of care}

On March $6^{\text {th }} 2020$, when COVID-19 pandemic became real in Italy, the Italian Society of Anesthesia, Analgesia,
Correspondence: Liliana Mazza, Policlinico Sant'Orsola-Malpighi, via Albertoni 15, 40138, Bologna, Italy. Tel.:

+39.051.2142253. E-mail:

liliana.mazza3@gmail.com

Key words: COVID-19; geriatric care; hospital care; assistance.

Acknowledgements: I would like to express my very great appreciation to the whole medical, nursing and health and social care assistants' staff of our Acute Geriatric Unit: their work and effort have been profoundly inspirational.

Contributions: LM wrote the article and revised the current literature; DP proposed several points of reflections discussed in the article; PC supervised the activities and furnished conclusions.

Conflict of interests: all authors declare no potential conflict of interests.

Received for publication: 17 April 2020.

Revision received: 8 May 2020.

Accepted for publication: 8 May 2020 .

This work is licensed under a Creative Commons Attribution-NonCommercial 4.0 International License (CC BY-NC 4.0).

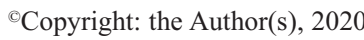

Licensee PAGEPress, Italy

Geriatric Care 2020; 6:9043

doi:10.4081/gc.2020.9043

Resuscitation and Intensive Care (SIAARTI) released a guideline document ${ }^{12}$ of clinical ethics recommendation for allocation of intensive care treatments, in order to maximize the benefits for those who have larger probability of survival. Two key points are: the set of an age limit for the admission to Intensive Care Unit (ICU) and the evaluation of comorbidities and functional status. It goes without saying that geriatric patients are not meant to be allocated in ICU, whereas their treatment should be built in lower intensity care settings. Our Acute Geriatric Unit has been asked to challenge this effort.

\section{Communication}

Physical aspect of healthcare workers is profoundly altered due to PPE, sacrificing either oral and non-oral communication. ${ }^{13}$ Facial expressions and eye-contact may not be perceived by patients below the face shield and the mask. Hand touch may lose its effectiveness in calming agitated and intimidated patients. Moreover, the volume of the voice is reduced due to the devices on the face, causing difficulties in interactions especially with subjects with hearing problems. Additionally, healthcare 
workers approaching to patients may be affected by the subjective perception of the risk of infection, which could further limit interaction.

\section{Prevention of delirium}

Delirium is the most common complication in hospitalized patients aged $>65$ and frequently remains underdiagnosed. ${ }^{14} \mathrm{It}$ may represent an exacerbating factor of COVID-19, worsened by social isolation due to prohibition for caregivers' visits, ${ }^{15}$ especially in patients with cognitive impairment or dementia. Communicative problematics could aggravate the situation, whereas non-pharmacological actions to prevent or treat delirium may not be as beneficial as described normally. ${ }^{16}$

\section{Isolation}

The need to contain the transmission of SARS-CoV-2 has made it essential to close the wards, where access of family members is prohibited. Social isolation means onset of depression, worsening of disorientation status and delirium. Caregivers involvement in geriatric wards in feeding, mobilizing and calming their relatives is invaluable and its absence in COVID-19 areas stands out dramatically, as long as assistance by healthcare professionals will have to bear it.

\section{Assistance reduced}

The release of SARS-CoV-2 through droplets may represent a cause of infection if safe distance is not observed. It is crystal clear that assistance to bedded patients, which are not functionally autonomous, represents a reason for close and frequent proximity to infected subjects. PPE performances seem to be comforting, ${ }^{17}$ but it is not blameworthy that operators' perception may conduct to minimize both continuous and sporadic contacts. Attending oral cavity cleaning ${ }^{18}$ or providing a glass of water may be not so obvious gestures as in the past. Consequences may appear in terms of oral infections, dehydration, renal impairment, dysphagia and aspiration pneumonia, which could dramatically affect respiratory condition overlapping on SARS-CoV-2-related interstitial pneumonia.

\section{Mobility}

Positive outcomes in mobilization are known in terms of reduction of prevention of pressure sores, ${ }^{19}$ reduction of length of stay and in lowering the risk of functional loss during the recovery. ${ }^{20}$ Moving a patient from bed to wheelchair and early assisted walking are physical activities that involve an extremely close contact, which may be currently not preferred by healthcare staff, as discussed above. Moreover, the use of
PPE may affect the agility of professionals in mobilization procedures. In addition, supervision of chaired patients is limited because of the reduced number of professionals involved in COVID-19 areas.

\section{End of life}

Caregivers' assistance at the end of life is considered an effective palliative treatment for improving quality of life. ${ }^{21}$ For those COVID-19 patients whose life expectancy is extremely reduced, the absence of caregivers and the impossibility, due to strict legal limitations, to have a loved one close, sometimes means dying alone.

\section{Improving assistance to COVID-19 elderly patients}

In this context, geriatricians are asked to re-invent and adapt to new standards of care. Although it is not currently possible to overcome all the difficulties discussed above, some innovative approaches can be implemented. The main are described as follows.

\section{Caregivers' involvement}

Phone calls from doctors to family members need to be effectuated daily, to make caregivers part of clinical paths and decisions. As typical of geriatric methodology, global and multidimensional evaluation bring to the construction of patient-centered program, whose sharing with caregivers is mandatory. ${ }^{22}$

\section{Contacts with life outside the ward}

Telephonic contacts between patients and family members have to be stimulated. Technological solutions should be found to make elderly patients able to connect via video-calls with their relatives, as face-toface contact may reduce loneliness and depression..$^{23}$ Personal accessories such as photographs or emotional objects should be furnished by familiars in order to relieve patients' anxieties.

\section{Team working}

All-round geriatric care consists of multiple allied health professionals who collaborate to best serve patients' needs. ${ }^{24}$ In COVID-19 era, feeding or giving a glass of water to a patient may become part of the medical examination, as a complement to nurses' activities. Specific professionals, such as physiotherapists, should be integrated to promote mobility and early assisted walking in ward, in order to protect the preexisting functional status.

\section{Do what needs to be done}

Benefits and risks of treatments must be evaluated in management of geriatric patients. Procedures and therapies should be proportionate to each singular clinical case and achieving small goals may be considered a target of action. Palliative care must be taken into consideration, especially in most severe cases. Discharge planning from acute care setting to lower settings of care or home dismission should be precociously undertaken, compatibly with the rules of Hygiene and Public Health, applying, albeit with the obvious precautions, the usual tools of the geriatrician for a patient-tailored discharge with the implementation of transitional care. ${ }^{25,26}$

\section{Conclusions}

Apart from infectivologists and anesthesiologists, geriatricians have seen their work dramatically changed in COVID-19 pandemic. Their role must be highlighted because of the large number of elderly patients involved. Our aim is to propose practical solutions to develop a proactive and further-thinking work methodology. Positive outcomes of these approaches will be investigated in further researches.

\section{References}

1. World Health Organization. Coronavirus disease 2019 (COVID-19) Situation Report 87; 2020. Available from: https:// www.who.int/docs/default-source/coronaviruse/situation-reports/20200416sitrep-87-covid-19.pdf?sfvrsn=952311 5a_2

2. Busetta G, Campolo MG, Panarello D. Letalità del COVID-19 nelle regioni italiane: sottostima dei casi positivi o carenza di strutture? Statistica e società; 2020. Available from: http:/www.rivista.sisstatistica.org/cms/?p=1082

3. Istituto Superiore di Sanità. Sorveglianza Integrata COVID-19 in Italia, aggiornamento 15 aprile 2020. Available from: https:/www.epicentro.iss.it/coronavirus/ bollettino/Infografica_15aprile\%20ITA. pdf

4. Istituto Superiore di Sanità. Caratteristiche dei pazienti deceduti positivi all'infezione da SARS-CoV-2 in Italia; 2020. Available from: https://www. epicentro.iss.it/coronavirus/sars-cov-2decessi-italia

5. Guan WJ, Ni ZY, Hu Y, et al. Clinical characteristics of coronavirus disease 
2019 in China. N Engl J Med 2020; 382:1708-20.

6. Huang C, Wang Y, Li X, et al. Clinical features of patients infected with 2019 novel coronavirus in Wuhan, China. Lancet 2020;395:497-506.

7. Polidori MC, Maggi S, Mattace-Raso F, Pilotto A. The unavoidable costs of frailty: a geriatric perspective in the time of COVID-19. Geriatric Care 2020;6: 8989.

8. Marengoni A, Angleman S, Melis R, et al. Aging with multimorbidity: a systematic review of the literature. Ageing Res Rev 2011;10:430-9.

9. Pilotto A, Custodero C, Maggi S, et al. A multidimensional approach to frailty in older people. Ageing Res Rev 2020;60: 101047.

10. Zucchelli A, Vetrano DL, Grande G, et al. Comparing the prognostic value of geriatric health indicators: a populationbased study. BMC Med 2019;17:185.

11. Centers for Disease Control and Prevention. Strategies to Optimize the Supply of PPE and Equipment; 2020. Available from: https:/www.cdc.gov/ coronavirus/2019-ncov/hcp/ppe-strategy/index.html

12. Italian Society of Anesthesia, Analgesia, Resuscitation and Intensive Care (SIAARTI). Clinical ethics recommendations for the allocation of intensive care treatments, in exceptional, resourcelimited circumstances; 2020. Available from: http://www.siaarti.it/SiteAssets/ News/COVID19\%20-\%20documenti\%20SIAARTI/SIAARTI\%20-\%20 Covid-19\%20-\%20Clinical\%20 Ethics\%20Reccomendations.pdf

13. Williams PA. Basic geriatric nursing, VI edition. Amsterdam: Elsevier; 2016.

14. Inouye SK, Westendorp RGJ, Saczynski JS. Delirium in elderly people. Lancet 2014;383:911-22.

15. LaHue SC, James TC, Newman JC, et al. Collaborative Delirium Prevention in the Age of COVID-19. J Am Geriatr Soc 2020 [Epub ahead of print].

16. Rivosecchi RM, Smithburger PL, Svec $\mathrm{S}$, et al. Nonpharmacological interventions to prevent delirium: an evidencebased systematic review. Crit Care Nurse 2015;35:39-49.

17. Fathizadeh H, Maroufi P, MomenHeravi M, et al. Protection and disinfection policies against SARS-CoV-2 (COVID-19). Infezmed 2020;28:185-91.

18. Izumi M, Takeuchi K, Ganaha S, et al. Effects of oral care with tongue cleaning on coughing ability in geriatric care facilities: a randomised controlled trial. J Oral Rehabil 2016;43:953-9.

19. Blackburn J, Ousey K, Taylor L, et al. The relationship between common risk factors and the pathology of pressure ulcer development: a systematic review. J Wound Care 2020;29:S4-S12.

20. Surkan MJ, Gibson W. Interventions to mobilize elderly patients and reduce length of hospital stay. Can J Cardiol 2018;34:881-8.

21. Sagha Zadeh R, Eshelman P, Setla J, et al. Strategies to improve quality of life at the end of life: interdisciplinary team perspectives. Am J Hosp Palliat Med 2018;35:411-6.

22. Bray-Hall ST. Transitional care: focusing on patient-centered outcomes and simplicity. Ann Intern Med 2012;157: 448-9.

23. Zamir S, Hennessy CH, Taylor AH, et al. Video-calls to reduce loneliness and social isolation within care environments for older people: an implementation study using collaborative action research. BMC Geriatr 2018;18:62.

24. Ellis G, Sevdalis N. Understanding and improving multidisciplinary team working in geriatric medicine. Age Ageing 2019;48:498-505.

25. Gonçalves-Bradley DC, Lannin NA, Clemson LM, et al. Discharge planning from hospital. Cochrane Datab Syst Rev 2016; Issue 1. Art. No.: CD000313.

26. Blaylock A, Cason CL. Discharge planning: Predicting patients' needs. J Gerontol Nurs 1992;18:5-9. 